\title{
BMJ Open Systematic review of qualitative studies on participants in the decision-making process about the location of care of the elderly
}

\author{
Gema Serrano-Gemes (D) ,,2 Manuel Rich-Ruiz (D) ,2,3 \\ Rafael Serrano-del-Rosal (i) ${ }^{1}$
}

To cite: Serrano-Gemes G, Rich-Ruiz M, Serranodel-Rosal R. Systematic review of qualitative studies on participants in the decision-making process about the location of care of the elderly. BMJ Open 2020;10:e036551. doi:10.1136/ bmjopen-2019-036551

- Prepublication history and additional material for this paper are available online. To view these files, please visit the journal online (http://dx.doi. org/10.1136/bmjopen-2019036551).

Received 19 December 2019 Revised 20 February 2020 Accepted 03 March 2020

Check for updates

(C) Author(s) (or their employer(s)) 2020. Re-use permitted under CC BY-NC. No commercial re-use. See rights and permissions. Published by BMJ.

${ }^{1}$ Instituto de Estudios Sociales Avanzados (IESA-CSIC), Consejo Superior de Investigaciones Cientificas, Córdoba, Spain ${ }^{2}$ Instituto Maimónides de Investigación Biomédica de Córdoba (IMIBIC), Universidad de Córdoba (UCO), Hospital Universitario Reina Sofía (HURS), Cordoba, Spain

${ }^{3}$ CIBER de Fragilidad y Envejecimiento Saludable (CIBERFES), Madrid, Spain

Correspondence to Gema Serrano-Gemes; gserrano@iesa.csic.es

\section{ABSTRACT}

Objectives To understand who are the participants in the decision-making process about the location of care of the elderly.

Design Systematic review of qualitative studies. Data sources The following databases were consulted: Web of Science, MEDLINE, Scopus, CINAHL, PsycINFO and SciELO (from the beginning until 29 November 2017). The bibliographical references in the studies that were finally included in the review were also searched.

Study selection The studies had to deal with the decision-making process (already experienced by the participants) on the location of care of the elderly (adults who are 65 or older), had to use a qualitative methodology and had to be written in English or Spanish.

Data extraction and synthesis A data extraction tool was used. Data analysis was conducted through the constant comparative method from Glaser and Strauss' grounded theory.

Results 46 studies were included in this review. Most of them were carried out in the USA, and in 21 of them the study population focused exclusively on the elderly. This review has found that there are many participants, with different roles and degrees of involvement, who may act jointly, separately or sequentially. These participants may be: the elders, family members, professionals and other relevant.

Conclusions The main result of this review has been the variability found on how this decision is made, even varying the way of acting/perceiving the situation of the involved persons on certain occasions, simply due to the influence of some of the other groups of participants studied. Besides, this review has focused its results on the main participant in this process, the elders and how their family members interact with them when it comes to making this decision. This has allowed relevant results to be obtained about roles and degrees of involvement. PROSPERO registration number CRD42018084826.

\section{INTRODUCTION}

Decision making in healthcare is very difficult. ${ }^{1}$ Throughout the literature, there are different models for the decision-making process, the most widely known being: the paternalistic model, ${ }^{2-4}$ the professional-as-agent model, ${ }^{24}$
Strengths and limitations of this study

- This review has synthesised and analysed in depth 46 studies including qualitative evidence on who the participants are, and their degree of involvement, in the decision-making process on the location of care of the elderly.

- The review has performed an analysis of the quality of the studies, as well as a study of their relative contributions.

- More studies are still needed to deal with this decision-making process from the point of view of healthcare and social services professionals, and other relevant participants, mainly friends and neighbours.

the informed decision-making model ${ }^{2-4}$ and the shared decision-making model. ${ }^{2-4}$

All these models may be analysed according to who is deliberating, how the exchange of information takes place and who the people responsible for the decision are. ${ }^{3}$

Among them, the shared decision-making model has proven to be an adequate, feasible and suitable way to deal with the clinical encounter at present. ${ }^{5}$ This is also important, among other reasons, because of its capacity to forge a new relation between professionals and individuals, ground on collaboration and also because persons want to be more implicated than they presently are in the decisionmaking process on their own well-being and healthcare. ${ }^{6}$

This shared character has multiple benefits: both the persons getting care and the ones providing it are able to comprehend what is significant for the other one; persons feel empowered and aided to make informed decisions and achieve a shared decision on their care; and healthcare and social services professionals may adapt the treatment or care to the individual's needs. ${ }^{7}$ 
But, apart from that, shared decision making is a necessary element to optimise the usage of the scant resources in healthcare, ${ }^{5}$ which has the potential to improve the way in which the resources are distributed and to reduce unjustified clinical variation. ${ }^{6}$

However, despite all its benefits, the shared decisionmaking model is not an everyday practice. ${ }^{8}$ In fact, many patients do not even expect to take part in decision making, ${ }^{8}$ thus being a barrier for shared decision making when patients do not want to be involved, preferring to have a passive role. ${ }^{9}$ As a matter of fact, according to the results of a systematic review of literature, patients assume that the role of 'normal' patients is to be passive and to expect clinicians to make the decisions. ${ }^{9}$

In the specific case of the elderly, a recent review reports contradictory results in this regard, finding both studies pointing to the preference of the aged for a passive role and for an active participation. ${ }^{1}$ The literature shows how the elderly, even if they do not wish to play an active role in medical decision making, want to be informed about their situation, as well as they consider it important to be listened to when they explain how they feel or what they think. $^{10}$

Together with their preference or opposition to participate actively, it is important to consider the attitudes of healthcare workers, as the bibliography also shows discriminatory attitudes on the basis of age in healthcare services, ${ }^{11}$ revealing healthcare workers who think that elderly patients are not able to take part in the decisions on the healthcare they receive. ${ }^{11}$ Those prejudices end up turning into attitudes of exclusion, such as, for instance, not asking elders about their preferences regarding care. ${ }^{11}$

In short, the literature points out the need for more research on how the elderly make decisions about their health. ${ }^{1}$ To do it adequately, planning and adapting their preferred level of involvement in the decision-making process has the potential to prevent hospitalisation and rehospitalisation, and to maintain their independence. ${ }^{1}$

As a result, this research has focused on a specific event, relocation, which entails a big change in the lives of most persons, ${ }^{12}$ usually seen as a stressful experience. ${ }^{12}$ If this is emotionally significant at any moment in life, it is particularly so in old age ${ }^{13}$ In addition, the elders being relocated is a growing group of people. ${ }^{14}$

Therefore, our research question in this paper is: who takes part in the decision-making process about the location of care of the elderly? The objective of this review would thus be to synthesise the existing evidence obtained using qualitative methodology in order to achieve a deep understanding of who takes part in the decision-making process about the location of care of the elderly.

This review is part of a broader review of the study of how the decision-making process takes place on the location of care of the elderly, which focused on three very important aspects: who the participants are, their experiences and the motives/reasons involved in the decisionmaking process. Due to the large amount of information found in the literature and its relevance, the authors of the review decided to answer each of the research questions separately.

\section{METHODS \\ Design}

To synthesise the existing evidence, we performed a systematic review of qualitative studies, which was conducted according to Preferred Reporting Items for Systematic Reviews and Meta-Analyses statement ${ }^{15}$ (online supplementary file 1) and the Enhancing Transparency in Reporting the Synthesis of Qualitative Research statement. ${ }^{16}$

Systematic review has been registered in the PROSPERO database.

\section{Data sources}

The following databases were consulted: Web of Science (core collection of Web of Science), MEDLINE (through PubMed), Scopus, CINAHL Complete (through EBSCOhost), PsycINFO (through ProQUEST) and SciELO Citation Index (through Web of Science).

The search in the databases was developed from the beginning of the databases to 29 November 2017.

The different search strategies used in each database are accurately shown in the published review protocol (online supplementary file 2). ${ }^{17}$

In addition, we reviewed the reference list of the papers which have been finally included, searching all the possible relevant papers.

\section{Study selection}

Eligible studies were those dealing with the decisionmaking process (already experienced by the participants) on the location of care of the elderly (adults who were 65 or older), and reporting qualitative research data.

Studies had to be written in English or Spanish, because these are the languages spoken by the reviewers.

More detailed information about the eligibility criteria used can be consulted in the published review protocol. ${ }^{17}$

\section{Data collection process}

Before starting the article selection process, duplicate citations obtained from the different databases were eliminated.

Thus, first the titles and abstracts of all the obtained citations were screened. Afterwards, the full-texts papers of those citations of interest were read, taking into account the inclusion and exclusion criteria to select those suitable for inclusion.

This process was carried out by two reviewers independently, who met to discuss their impressions periodically, consulting a third reviewer only in cases where there was disagreement.

The detailed data collection process is shown in a flow chart (figure 1). 


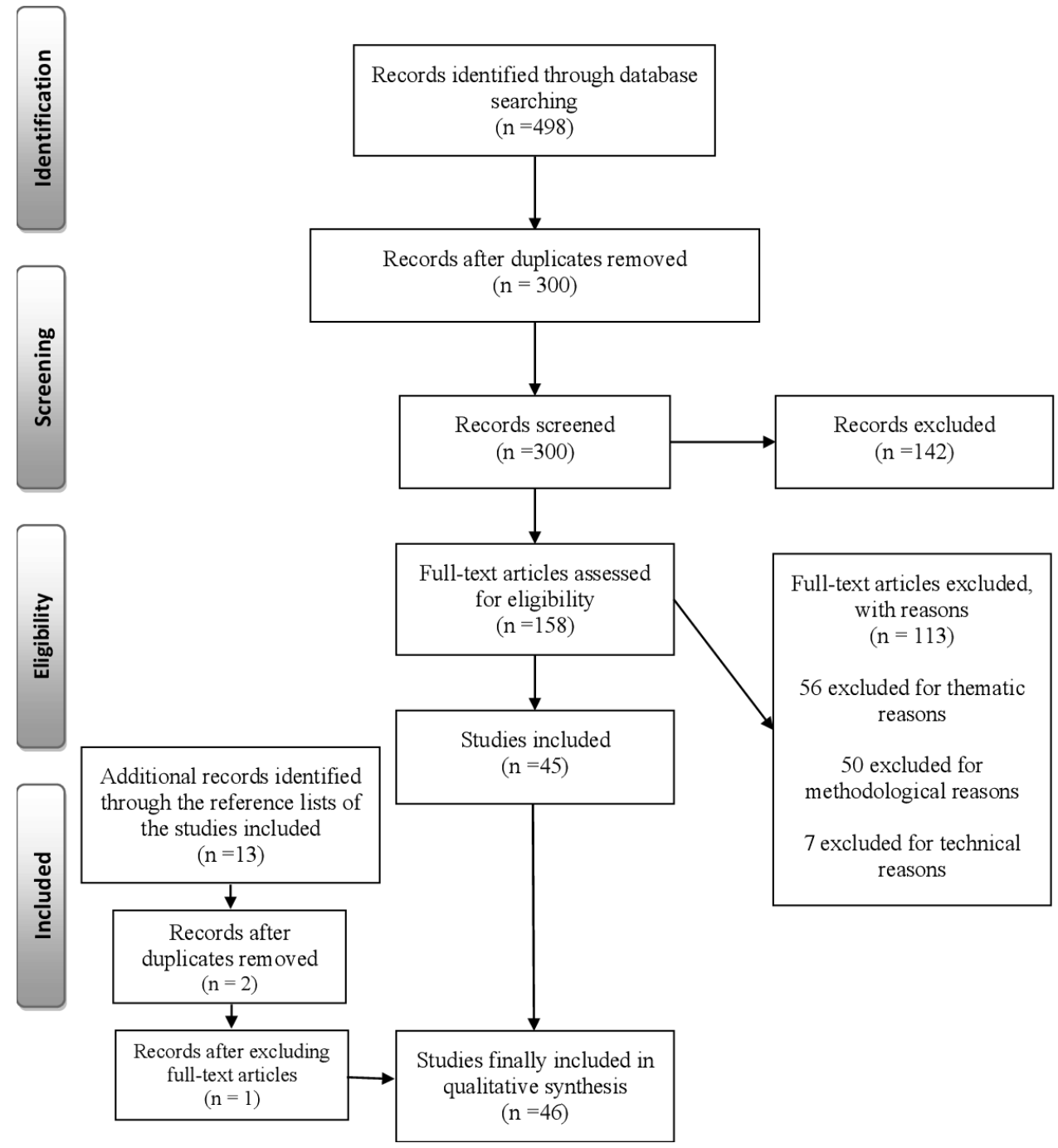

Figure 1 Flow chart (modified Preferred Reporting Items for Systematic Reviews and Meta-Analyses 2009 flow diagram). ${ }^{15}$

\section{Data extraction}

A tool for data extraction was used to extract information about the title, year of publication, country, language, authors, objective, design/methodological basis, sample, techniques/methods for information collection, data analysis methods/techniques, ethical considerations, results, final conclusion, strengths and limitations and comments by the reviewers.

The descriptive information has been classified in online supplementary file 3 , while the information regarding the results was first classified and subsequently analysed.

The entire process was developed by two of the authors, and in cases where there was no agreement, the third author mediated.

\section{Quality assessment}

The quality of the studies included in this review was evaluated using the Critical Appraisal Skills Programme Español (CASPe): Plantilla para ayudarte a entender un estudio cualitativo. ${ }^{18}$ This evaluation, together with the relative contributions of different studies to the results of this review according to their quality (taking into account a process proposed by other authors) ${ }^{19}$ is shown in table 1 .

Thus, this review understands as a relative contribution each of the contributions of the studies included in our review to the results of the same one. Taking this into account, a score of 1 means that the study has provided information to a single aspect, while a score of 20 means that that study has contributed on 20 occasions to the results of the review.

On the other hand, to give a score to the quality of the included papers, the score and classification system proposed by Butler $e t a l^{20}$ has been used: every 'Yes' scores 1 point, every 'Not sure' scores 0.5 points and every 'No' scores 0. Later, that same author classifies them into three categories: high-quality paper (scores 9-10), moderate-quality paper (scores 7.5-9), low-quality paper (less than 7.5) and those under 6 points are excluded. ${ }^{20}$ In this review, however, the quality of the studies was not part of the inclusion or exclusion criteria, and that is why the studies have not been excluded because of their quality. 
Table 1 Quality assessment and relative contributions

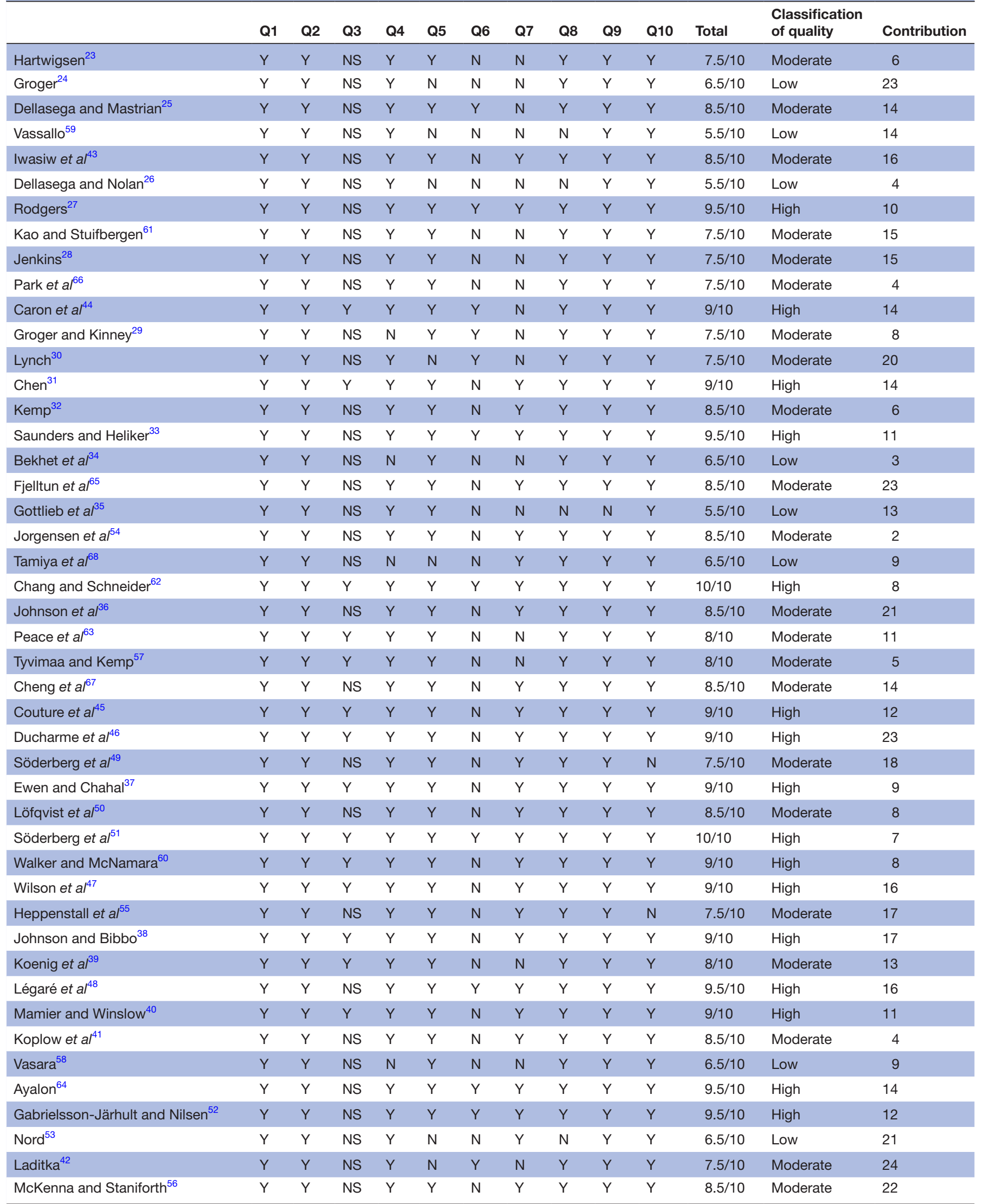

Source: own elaboration based on the information obtained from the 46 articles that make up this systematic review.

Y, yes; NS, not sure; N, no; Q, question. 
The entire process was developed by two of the authors, and in cases where there was no agreement, the third author mediated.

\section{Patient and public involvement statement \\ Patients and public are not involved in this study.}

\section{Data analysis}

The data analysis was carried out through the constant comparative method ${ }^{21}$ from Glaser and Strauss' grounded theory. ${ }^{22}$ First, a complete reading of the results and conclusions of the different studies was carried out. Subsequently, the information corresponding to the objective of this review (who takes part in the decision about the location of care of the elderly) was identified, using the authors' interpretations and textual quotes. Finally, categories and subcategories emerged, whose origin was the main topic of the study, which can be found in the Results section.

The entire process was developed by two of the authors, and in cases where there was no agreement, the third author mediated.

\section{RESULTS}

Forty-six studies were included in this systematic review (figure 1), all of them written in English. These studies were carried out in 14 countries: 20 in the USA, ${ }^{23-42} 6$ in Canada, ${ }^{43-48} 5$ in Sweden, ${ }^{49-53} 3$ in New Zealand, ${ }^{54-56}$ 2 in Finland, ${ }^{57} 582$ in Australia, ${ }^{59} 602$ in Taiwan, ${ }^{6162} 2$ in the $\mathrm{UK}^{2663}$ ( 1 in England), ${ }^{63} 1$ in Germany, ${ }^{50} 1$ in Israel, ${ }^{64}$ 1 in Norway, ${ }^{65} 1$ in South Korea, ${ }^{66} 1$ in China ${ }^{67}$ and 1 in Japan. ${ }^{68}$ Seven of these studies have been published in the last 5 years. ${ }^{41} 425253565864$ As far as the participants are concerned, 21 of the studies focused exclusively on elders, ${ }^{23} 24293133-38434750-53$ 56-58 606312 only on family members, ${ }^{25-27} 4144-4648496162665$ included elders and family members, ${ }^{32} 395559643$ included professionals, family members and elders, ${ }^{28} 54672$ focused on family members and professionals, ${ }^{40} 652$ dealt with the researcher's personal experience as a family member of an involved elder ${ }^{3042}$ and 1 used patient records. ${ }^{68}$ For a detailed view of the characteristics of the included studies, please refer to the online supplementary file 3 .

As for the quality of the included studies, most are of a moderate quality (22 papers). ${ }^{23} 2528-3032363941-43495054-57616365-67$ Meanwhile, 16 papers are of a high quality, ${ }^{2731} 3337384044-4851526062642$ of them achieving the highest score. ${ }^{5162}$ On the contrary, only 8 out of the 46 included papers are of a low quality. ${ }^{2426343553585968}$

As regards their relative contribution to the obtained results, it may be observed that there is no connection between the studies' quality and their relative contribution to the review's results, since there are papers which have obtained a low quality score and have had a high score in relative contribution, as is the case for Groger ${ }^{24}$ or the opposite, with a high quality and a low contribution, as is the case for Söderberg et $a l^{51}$ The paper with the highest relative contribution is Laditka ${ }^{42}$ (with a moderate quality), and the one with the lowest relative contribution is Jorgensen $e t a p^{54}$ (with a moderate quality). For more details, see table 1.

Below is the summary of the results with the corresponding categories obtained. The original quotes $(\mathrm{OQ})$ from the papers included in the review, which exemplify the categories of interest, are listed in detail in online supplementary file 4 .

\section{Participants in the decision-making process}

One of the most important characteristics found throughout this review on the decision-making process to choose the location of care of the elderly is the existence of many participants with different roles and degrees of involvement.

To sum up, these participants may be classified into: the elderly persons themselves, ${ }^{23-68}$ family members, ${ }^{24-33} 36$ 38-49 51 53-56 59 61-68 healthcare and social services professionals ${ }^{23-25} 272830364042-4951-535556585961-636568$ and other relevant participants. ${ }^{25} 273133363740424648566267$

\section{The elders}

The participation of the elder in the process to decide where he or she will receive care ranges from a complete lack of participation to an active decision made on their own.

\section{Active participation}

In this review, the active participation of elderly people in this decision-making process has been understood differ-

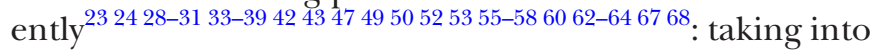
account both the decisions and actions performed by the elders on their own, and those where they were accompanied by other people.

\section{On their own}

According to our results, in most cases, the elders are the decision owners, making it actively and responsibly, even getting involved in the different roles concerned in this decision-making process ${ }^{232428293134-39434950525356-586062-646768}$ (OQ1). ${ }^{24}$

By doing so, getting involved in the decision-making process, many elders are able to keep control and to decide, ${ }^{23} 35505257$ which allows them to suitably manage their everyday life and to stay at home, ${ }^{35} 5052$ but also, at the same time, to be ready for a possible relocation ${ }^{50}$ (OQ2). ${ }^{52}$

In fact, on some occasions, the decision is even taken pre-emptively, ${ }^{29} 35535760$ which leads to the elderly person to relocate prematurely/pre-emptively ${ }^{29} 35560$ (OQ3). ${ }^{60}$

However, on other occasions, the elders act in the completely opposite way, postponing the decision. ${ }^{35} 5063$ These persons do not only postpone the decision, they do not even want to talk about it, ${ }^{353}$ therefore being unable to act pre-emptively. ${ }^{35}$ This makes them even get to delegate the responsibility for taking the decision on when to relocate. $^{3550}$ 


\section{Accompanied}

The second most common situation is when the elderly

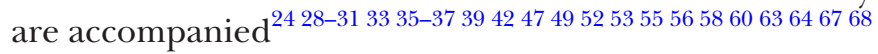
by different people in this process.

To a greater extent, they are accompanied by their families, ${ }^{24}$ 28-31 33 35-373942 474952 5355 5658636467 followed by different healthcare and social services professionals 242830495253565863 and, lastly, by other relevant participants, ${ }^{31333637535660}$ such as friends. ${ }^{31} 33363756$ All these people may provide either a positive or a negative support, and they may have a different degree of involvement.

\section{Some participation}

A mid-point in the responsibility gradient in decision making would be when the elderly person has some participation in the decision making. ${ }^{2430-3236383942-4648535961646567}$ This means that, as opposed to what is said in the previous sections, where the elder would actively participate in the decision-making process, in this category the elders find themselves involved in the process somehow, but not with a complete responsibility.

Thus, it is also the case that sometimes the elderly simply accept decisions made by other people, so they do not actually get to make the decision ${ }^{24} 30-3239424346536467$ $\left(\mathrm{OQ}_{4} \mathrm{~A}^{64} / \mathrm{OQ}^{4 \mathrm{~B}^{43}}\right)$.

On some occasions, the decision is accepted only after a process of negotiation of the different proposals made by family members. ${ }^{30} 5967$

Nevertheless, even if the elders are not the ones deciding, their participation, although partial, influentially contributes to the final decision. In many of these cases, the elders are listened to and their opinions are respected and taken into account ${ }^{3042444665}$ (OQ5). ${ }^{46} \mathrm{On}$ other occasions, even though at first their family members try to convince them, in the end, they end up respecting the elder's opinion ${ }^{65}$ (OQ6), ${ }^{65}$ even postponing the decision to relocate because the elder refused to do so 30424665 $(\mathrm{OQ} 7){ }^{46}$

\section{The elders do not decide}

Lastly, it bears mentioning that on many occasions there are cases where the elders to not participate in any way $^{24-273638404143-485153555661656668}$ in the decision-making process, even if they have no cognitive problems ${ }^{48}$; the decision is simply taken for them ${ }^{24-273638404143-485153555661656668}$ (OQ8). ${ }^{38}$

Many of this elders are not even consulted, but are only informed of the decision once it is already made 244347555665 (OQ9). ${ }^{24}$ On the other hand, some elders simply realised that they were being relocated and they would not go back to their previous homes. ${ }^{4751}$

Finally, in the most negative extreme of this lack of participation, there are elders who claim having been deceived ${ }^{38}$ during the decision-making process (OQ10). ${ }^{38}$

\section{Family members}

Considering the results obtained in this review, we decided to analyse the role of the family in the decisionmaking process, according to what their behaviour was like in relation to the elder affected by the decision.

Taking this perspective into account, family members, in general, usually adopt two completely opposite kinds of behaviour: taking into account the elder, ${ }^{24}$ 30-33 $363839424345-495355565961646567$ or not taking him or her into account. ${ }^{24} 253638394346-4853596165$

\section{Taking into account the elder}

In general, those family members who act taking into account the concerned elder usually adopt positive behaviours $^{24}$ 30-33 $3639424345-474953555961646567$ throughout this process. Some examples of this kind of positive behaviours would be those cases where the family members take on a mediator role so that the wishes and decisions of the elders are fulfilled ${ }^{304249} 55$ (OQ11), ${ }^{55}$ also being an example when they listen to and respect the preferences of the elder, ${ }^{30} 39424649556467$ and even, if necessary, postpone the relocating decision due to the refusal of the elderly persons ${ }^{30424649}$ (OQ12). ${ }^{46}$

However, the fact is that taking into account the elders does not always mean having a positive behaviour. In fact, on some occasions, family members get to adopt different negative behaviours ${ }^{24} 38484956 \quad 616465$ as regards the decision-making process about the elders. Some examples of these negative behaviours would be to outright lie to the elders ${ }^{38}{ }^{48}$ (OQ13) ${ }^{48}$ or to use persuasion. ${ }^{49}$ Even so, although some family members tried to use persuasion, ${ }^{496165}$ in some cases, in view of the elders' refusal, they did not get to act against their will ${ }^{65}$ (OQ14). ${ }^{65}$

There are other cases in which, due to the persistence of family members, the elders end up relocating, ${ }^{64}$ or the family members force the elders, ${ }^{2456}$ even to relocate without their partners. ${ }^{56}$

\section{Not taking into account the elder}

Despite the fact that most of the studies included in this review deal with situations where family members take into account the elders in some way, this is not always the case. In fact, the situations where family members do not take the elder into account in any way usually occur due to the elder's cognitive impairment ${ }^{4661}$ (OQ15). ${ }^{46}$ However, even if this may be the most common situation, our results have also found references to situations where the elders are excluded despite not having cognitive impairments. ${ }^{48}$

The family members who behave like this usually decide without the participation of the elders, ${ }^{25} 363843$ just informing them once the decision has already been made 243638394765 (OQ16). ${ }^{38}$ Nonetheless, in some cases the exclusion of the elder is premeditated, deciding to relocate him or her as a form of punishment. ${ }^{59}$

\section{Professionals}

As for healthcare and social services professionals, there is a broad range of both types of professionals involved and the way they are referred to. 
The most usual way to name them in the studies is 'healthcare professionals', ${ }^{274-4653596365}$ although 'service provider' is also used.$^{28}$

However, the most common way to refer to the professionals is to name the different professional groups involved in this process (from the most often named to the less often named): physician, ${ }^{23242728404445474953596265}$ social worker, ${ }^{24} 272836444548535968$ nurse, ${ }^{30} 364445475965$ care manager/case manager, ${ }^{2842444951}$ home healthcare leader ${ }^{65}$ and occupational therapist. ${ }^{44}$

There are also references to different institutions involved in the process, as may be the ageing and home healthcare agencies, ${ }^{28}{ }^{42}$ and even home healthcare services $^{42}$; or the geriatric evaluation units. ${ }^{44}$

On the other hand, the studies also refer to professionals linked to certain institutions, such as evaluators linked to communities, ${ }^{42}$ or the residence directors. ${ }^{46} 56$

Finally, it bears mentioning a particularly divergent case as regards the participation of professionals, and it is the case of hospital staff. ${ }^{25283040425255565861}$ The different studies include references to a wide range of attitudes, from an almost complete absence and lack of interest for the elder's living conditions, ${ }^{42}$ focussing exclusively on medical issues ${ }^{42}$; to their involvement in the discussion of plans, care options and information 2528304052565961 or to even completely taking on the decision on where the elder should receive care ${ }^{55} 5861$ (OQ17) ${ }^{55}$

\section{Other relevant participants}

Lastly, this review has also found a fourth category of participants, which would be that of other relevant participants, which includes all those people who are relevant and influential in the decision-making process, but are not included in the previously mentioned categories.

In this group, friends and neighbours 273133363740424648566267 are the participants who seem to be the most important and influential for the rest of participants, being essential, for instance, to validate the decision, that is, to recognise the decision taken as appropriate $^{25}$ (OQ18). ${ }^{25}$

This category also includes support groups, ${ }^{40}$ and even, on some occasions, people on the street are also included in the category. ${ }^{25}$

\section{DISCUSSION}

\section{Principal findings}

The review conducted here included 46 articles of interest with qualitative data, thanks to which it has been possible to respond to the objective of this review, to understand in depth who takes part in the decision-making process about the location of care of the elderly.

Thus, the results of this review identify several involved participants, with different roles and degrees of involvement. These participants are the elders affected by the decision, their family members, the healthcare and social services professionals, and other relevant participants, such as friends and neighbours.
The elders themselves, the people mainly affected by this decision, may act on their own, be accompanied (mainly by their families), just have some participation in the decision or not participate at all. Among all of them, acting on their own has been the option with the highest number of references in our results. This coincides in some way with the literature, which shows how elders want to be involved in making autonomous decisions in different fields, like those linked to their care, treatment and everyday life. ${ }^{69}$ However, another recent review of the literature, which addresses the decision of location of care and end of life, it points out how most older people were excluded from the decision totally, although they also note that there were elders who were actively included or even made autonomous decisions, although they were not in the majority. ${ }^{70}$

Because of these differences with respect to whether or not the older person is involved in the decision-making process about the location of care, further research is needed to see which factors influence and act directly on not only the capacity or possibilities for participation, but also on the desire to participate, to take part actively, and even to act pre-emptively.

On the other hand, in spite of family members usually taking into account the elders, we have also found situations where they act without taking the elders into account, usually when there are cognitive problems. Our results coincide with those of a recent review, which shows how some carers both talk about the decision with older people and not talk about it, noting how in some cases older people could not be implicated because of cognitive problems. ${ }^{70}$ These reactions seem to be supported by the literature, since, as a recent systematic review on dementia claims, when dementia progresses, the person suffering from it loses the mental capacity to make more complex decisions, and the caregiver turns into the surrogate decision-maker, changing the couple's relationship and reverting the roles in parents and children. ${ }^{71}$

As for professionals, this review shows a wide range of variety, roles and degree of involvement from the professionals taking part in this decision. In the review of Garvelink $e t a l,{ }^{70}$ the role of health professionals is also pointed out, seeing that they offer information, instruct the decision makers, initiate the decision or even are the ones who make the decision, among other roles. ${ }^{70}$ However, Garvelink's review does not specify the different types of professionals involved, as it does our review, the physician being the professional most often mentioned in the reviewed papers in our review.

Lastly, apart from the three above mentioned main groups of participants, there is another group of people who are relevant in the decision, including, for instance, support groups, but, above all, friends and neighbours, who are not only mentioned more often, but they seem to have a greater influence. Among other things, they help to validate the decisions, which was already mentioned in the systematic review by Jacobson $e t a l^{72}$ on the experiences of carers of elders who have been relocated to a facility. This 
review's results pointed out that carers usually felt that they had a minimum control in the decision making and in the relocating process, and that they sought validation from friends, family members and professionals. ${ }^{72}$

\section{Limitations}

This systematic review has some limitations. The main one is that it was not always possible to count on the perceptions or opinions of participants in the decisionmaking process directly, but on certain occasions it was only possible to have access to these experiences on the basis of the accounts of other participants in the process.

In addition, given the magnitude of de quantity of information found and analysed, we have chosen to analyse the interpretations made by the authors of the studies included, summarising and extracting, in certain cases, some direct quotations, because of their greater clarity and relevance to the review's results.

\section{Future research}

First of all, regarding future lines of research on this topic, we consider that more research whose object of study is the professionals involved in the decision-making process, as well as other relevant participants, because few articles have been found that primarily address their views. These studies would be not only interesting from an academic point of view, but could also help directly to both professionals facing this decision in the future and elders themselves, family members and their immediate environment, by bringing out their unique and personal perspectives.

Furthermore, although many primary qualitative studies have been found, they focus only on 14 countries, most of them Western countries. Therefore, it would be interesting if more research were carried out on the decisionmaking process of older people in different areas of the world (with different cultural norms and values). Thus, this process could be studied in more detail and depth, and it could be possible to see whether or not there are differences in who participates in this decision and how the participants relate to each other.

\section{CONCLUSION}

The main result of this review has been the high variability found in the literature on how the decision on the location of elderly care is taken. There is no pattern or single way to proceed, and, on some occasions, the way the people involved act or perceive the situation varies due to the influence of some of the other groups of participants studied.

Despite that, this review has obtained relevant and really noteworthy results as far as the roles and degrees of involvement are concerned, thanks to having focused on the main participants in this process, those who are directly affected by the decision: the elders.

Thus, the different ways in which the elder is involved in the decision-making process have been analysed, to a greater or lesser extent, as well as how those closest to them, their family members, relate to the elders when it comes to making this decision. In this regard, it is highly interesting how some behaviours that may seem positive a priori, such as taking into account the elder, are not always linked to positive behaviours from the family members.

However, the existence of other participants in the literature also bears mentioning, who have been classified into two big groups: healthcare and social services professionals (physician being the most often mentioned category, followed by social worker and nurse), and other relevant participants in the decision-making process (the elder's friends and neighbours being the most often mentioned). Nevertheless, more research is still needed to go in-depth on their experiences and/or opinions throughout this process.

Contributors G-S-G conceived the study and the study design. G-S-G developed and executed the search strategy. G-S-G, R-S-d-R and M-R-R prepared the draft of the systematic review, edited the draft systematic review and read and approved the final manuscript.

Funding This work was supported by Ministerio de Educación, Cultura y Deporte para la Formación de Profesorado Universitario (Gobierno de España), the first author being recipient of an aid for the training of university teachers.

Competing interests None declared.

Patient and public involvement Patients and/or the public were not involved in the design, or conduct, or reporting, or dissemination plans of this research.

Patient consent for publication Not required.

Ethics approval This systematic review did not require ethical approval.

Provenance and peer review Not commissioned; externally peer reviewed.

Data availability statement This review is part of a broader review. All data relevant to this review are included in the article or uploaded as supplementary information.

Open access This is an open access article distributed in accordance with the Creative Commons Attribution Non Commercial (CC BY-NC 4.0) license, which permits others to distribute, remix, adapt, build upon this work non-commercially, and license their derivative works on different terms, provided the original work is properly cited, appropriate credit is given, any changes made indicated, and the use is non-commercial. See: http://creativecommons.org/licenses/by-nc/4.0/.

\section{ORCID iDs}

Gema Serrano-Gemes http://orcid.org/0000-0002-4071-6981

Manuel Rich-Ruiz http://orcid.org/0000-0003-3317-267X

Rafael Serrano-del-Rosal http://orcid.org/0000-0002-9488-8295

\section{REFERENCES}

1 King L, Harrington A, Linedale E, et al. A mixed methods thematic review: health-related decision-making by the older person. $J$ Clin Nurs 2018;27:e1327-43.

2 Charles C, Gafni A, Whelan T. Shared decision-making in the medical encounter: what does it mean? (or it takes at least two to tango). Soc Sci Med 1997;44:681-92.

3 Charles C, Gafni A, Whelan T. Decision-Making in the physicianpatient encounter: revisiting the shared treatment decision-making model. Soc Sci Med 1999;49:651-61.

4 Montori VM, Elwyn G, Devereaux P, et al. Decision making and the patient. In: Users' Guides to the Medical Literature: A Manual for Evidence-Based Clinical Practice. $3^{\mathrm{a}}$ ed. New York: McGraw-Hill, 2015: 547-59.

5 Légaré F, Thompson-Leduc P. Twelve myths about shared decision making. Patient Educ Couns 2014;96:281-6.

6 NHS England. Why is shared decision making important? Available: https://www.england.nhs.uk/shared-decision-making/why-is-shareddecision-making-important/ [Accessed 27 Oct 2019].

7 NICE National Institute for Health and Care Excellence. Nice: shared decision making. Available: https://www.nice.org.uk/about/what-wedo/our-programmes/nice-guidance/nice-guidelines/shared-decisionmaking [Accessed 27 Oct 2019]. 
8 Stiggelbout AM, Van der Weijden T, De Wit MPT, et al. Shared decision making: really putting patients at the centre of healthcare. BMJ 2012;344:e256.

9 Joseph-Williams N, Elwyn G, Edwards A. Knowledge is not power for patients: a systematic review and thematic synthesis of patientreported barriers and facilitators to shared decision making. Patient Educ Couns 2014:94:291-309.

10 Ekdahl AW, Andersson L, Friedrichsen M. "They do what they think is the best for me." Frail elderly patients' preferences for participation in their care during hospitalization. Patient Educ Couns 2010;80:233-40.

11 Organización Mundial de la Salud. Informe mundial sobre E envejecimiento Y La salud. Ginebra: OMS, 2015.

12 Schulz R, Brenner G. Relocation of the aged: a review and theoretical analysis. J Gerontol 1977;32:323-33.

13 Oswald F, Rowles GD. Beyond the relocation trauma in old age: New trends in elders' residential decisions. In: New dynamics in old age: individual, environmental and societal perspectives. New York: Routledge, 2017: 127-52.

14 Bekhet AK, Zauszniewski JA, Resourcefulness ZJA. Resourcefulness, positive cognitions, relocation controllability and relocation adjustment among older people: a cross-sectional study of cultural differences. Int J Older People Nurs 2013;8:244-52.

15 Moher D, Liberati A, Tetzlaff J, et al. Preferred reporting items for systematic reviews and meta-analyses: the PRISMA statement. PLoS Med 2009;6:e1000097.

16 Tong A, Flemming K, Mclnnes E, et al. Enhancing transparency in reporting the synthesis of qualitative research: ENTREQ. BMC Med Res Methodol 2012;12:181.

17 Serrano-Gemes G, Serrano-Del-Rosal R, Rich-Ruiz M. Decision-Making on the location of care of the elderly: protocol for a systematic review of qualitative studies. BMJ Open 2018;8:e022411.

18 Cano Arana A, González Gil T, Cabello López JB. Plantilla para ayudarte a entender un estudio cualitativo. In: CASPe. Guías CASPe de Lectura Crítica de la Literatura Médica. Alicante: CASPe: Cuaderno III, 2010: 3-8.

19 Thomas J, Harden A. Methods for the thematic synthesis of qualitative research in systematic reviews. BMC Med Res Methodol 2008;8:45.

20 Butler A, Hall H, Copnell B. A guide to writing a qualitative systematic review protocol to enhance evidence-based practice in nursing and health care. Worldviews Evid Based Nurs 2016;13:241-9.

21 Glaser BG. The constant comparative method of qualitative analysis. Soc Probl 1965;12:436-45.

22 Glaser BG, Strauss AL. The Discovery of Grounded Theory: Strategies for Qualitative Research. New York: Aldine Publishing Company, 1967.

23 Hartwigsen G. Older widows and the transference of home. Int $J$ Aging Hum Dev 1987;25:195-207.

24 Groger L. Decision as process: a conceptual model of black elders nursing home placement. J Aging Stud 1994;8:77-94.

25 Dellasega C, Mastrian K. The process and consequences of institutionalizing an elder. West J Nurs Res 1995;17:123-40.

26 Dellasega C, Nolan M. Admission to care: facilitating role transition amongst family carers. J Clin Nurs 1997;6:443-51.

27 Rodgers BL. Family members' experiences with the nursing home placement of an older adult. Appl Nurs Res 1997;10:57-63.

28 Jenkins CL. Care arrangement choices for older widows: decision participants' perspectives. J Women Aging 2003;15:127-43.

29 Groger L, Kinney J. CCRC here we come! reasons for moving to a continuing care retirement community. $J$ Hous Elderly 2007;20:79-101.

30 Lynch JS. The cycle of relocation: one family's experience with elder care. Topics in Advanced Practice Nursing eJournal 2006;6:8p.

31 Chen S. Elders' decisions to enter assisted living facilities: a grounded theory study. Southern Online Journal of Nursing Research 2008;8:1p.

32 Kemp CL. Negotiating transitions in later life: married couples in assisted living. J Appl Gerontol 2008;27:231-51.

33 Saunders JC, Heliker D. Lessons learned from 5 women as they transition into assisted living. Geriatr Nurs 2008;29:369-75.

34 Bekhet AK, Zauszniewski JA, Nakhla WE. Reasons for relocation to retirement communities: a qualitative study. West J Nurs Res 2009;31:462-79.

35 Gottlieb AS, Stoeckel KJ, Caro FG. Residential adjustment of elders: learning from experiences with parents and Peers. J Hous Elderly 2009;23:149-65.

36 Johnson R, Popejoy LL, Radina ME. Older adults' participation in nursing home placement decisions. Clin Nurs Res 2010;19:358-75.
37 Ewen $\mathrm{HH}$, Chahal J. Influence of late life stressors on the decisions of older women to Relocate into congregate senior housing. J Hous Elderly 2013;27:392-408.

38 Johnson RA, Bibbo J. Relocation decisions and constructing the meaning of home: a phenomenological study of the transition into a nursing home. J Aging Stud 2014;30:56-63.

39 Koenig TL, Lee $\mathrm{JH}$, Macmillan KR, et al. Older adult and family member perspectives of the decision-making process involved in moving to assisted living. Qualitative Social Work 2014;13:335-50.

40 Mamier I, Winslow BW. Divergent views of placement decisionmaking: a qualitative case study. Issues Ment Health Nurs 2014;35:13-20.

41 Koplow SM, Gallo AM, Knafl KA, et al. Family caregivers define and manage the nursing home placement process. J Fam Nurs 2015;21:469-93.

42 Laditka SB. "It Can't Happen Soon Enough." The Role of Readiness in Residential Moves by Older Parents. Gerontologist 2017;57:6-11.

43 Iwasiw C, Goldenberg D, MacMaster E, et al. Residents' perspectives of their first 2 weeks in a long-term care facility. $J$ Clin Nurs 1996;5:381-8.

44 Caron CD, Ducharme F, Griffith J. Deciding on institutionalization for a relative with dementia: the most difficult decision for caregivers. Can J Aging 2006;25:193-205.

45 Couture M, Ducharme F, Lamontagne J. The role of health care professionals in the decision-making process of family caregivers regarding placement of a cognitively impaired elderly relative. Home Health Care Manag Pract 2012;24:283-91.

46 Ducharme F, Couture M, Lamontagne J. Decision-Making process of family caregivers regarding placement of a cognitively impaired elderly relative. Home Health Care Serv Q 2012;31:197-218.

47 Wilson DM, Vihos J, Hewitt JA, et al. Examining waiting placement in hospital: utilization and the lived experience. Glob J Health Sci 2013:6:12-22.

48 Légaré $\mathrm{F}$, Stacey $\mathrm{D}$, Brière $\mathrm{N}$, et al. An interprofessional approach to shared decision making: an exploratory case study with family caregivers of one IP home care team. BMC Geriatr 2014;14:83.

49 Söderberg M, Ståhl A, Melin Emilsson U. Family members' strategies when their elderly relatives consider relocation to a residential home--adapting, representing and avoiding. J Aging Stud 2012;26:495-503.

50 Löfqvist C, Granbom M, Himmelsbach I, et al. Voices on relocation and aging in place in very old age--a complex and ambivalent matter. Gerontologist 2013;53:919-27.

51 Söderberg M, Ståhl A, Melin Emilsson U. Independence as a stigmatizing value for older people considering relocation to a residential home. European Journal of Social Work 2013;16:391-406.

52 Gabrielsson-Järhult F, Nilsen P. On the threshold: older people's concerns about needs after discharge from hospital. Scand J Caring Sci 2016;30:135-44.

53 Nord C. Free choice in residential care for older people - A philosophical reflection. J Aging Stud 2016;37:59-68.

54 Jorgensen $\mathrm{D}$, Arksey $\mathrm{H}$, Parsons $\mathrm{M}$, et al. Why do older people in New Zealand enter residential care rather than choosing to remain at home, and who makes that decision? Ageing Int 2009;34:15-32.

55 Heppenstall CP, Keeling S, Hanger HC, et al. Perceived factors which shape decision-making around the time of residential care admission in older adults: a qualitative study. Australas J Ageing 2014;33:9-13.

56 McKenna DM, Staniforth B. Older people moving to residential care in Aotearoa New Zealand: considerations for social work at practice and policy levels. ANZSWJ 2017;29:28-40.

57 Tyvimaa T, Kemp CL. Finnish Seniors' Move to a Senior House: Examining the Push and Pull Factors. J Hous Elderly 2011;25:50-71.

58 Vasara P. Not ageing in place: negotiating meanings of residency in age-related housing. J Aging Stud 2015;35:55-64.

59 Vassallo T. Systemic therapy and aged Respite care a neglected area. Australian and New Zealand Journal of Family Therapy 1995; $16: 73-80$

60 Walker E, McNamara B. Relocating to retirement living: an occupational perspective on successful transitions. Aust Occup Ther J 2013;60:445-53.

61 Kao HF, Stuifbergen AK. Family experiences related to the decision to institutionalize an elderly member in Taiwan: an exploratory study. Soc Sci Med 1999:49:1115-23.

62 Chang Y-P, Schneider JK. Decision-Making process of nursing home placement among Chinese family caregivers. Perspect Psychiatr Care 2010;46:108-18.

63 Peace S, Holland C, Kellaher L. 'Option recognition' in later life: variations in ageing in place. Ageing Soc 2011;31:734-57.

64 Ayalon L. Intergenerational perspectives on autonomy following a transition to a continuing care retirement community. Res Aging 2016;38:127-49. 
65 Fjelltun A-MS, Henriksen N, Norberg A, et al. Carers' and nurses' appraisals of needs of nursing home placement for frail older in Norway. J Clin Nurs 2009;18:3079-88.

66 Park M, Butcher HK, Maas ML. A thematic analysis of Korean family caregivers' experiences in making the decision to place a family member with dementia in a long-term care facility. Res Nurs Health 2004;27:345-56.

67 Cheng Y, Rosenberg MW, Wang W, et al. Access to residential care in Beijing, China: making the decision to relocate to a residential care facility. Ageing Soc 2012;32:1277-99.

68 Tamiya N, Chen L-M, Sugisawa H. Caregivers' decisions on placement of family members in long-term care facilities in Japan: analysis of caregiver interviews. Soc Behav Pers 2009;37:393-410.
69 Fjordside S, Morville A. Factors influencing older people's experiences of participation in autonomous decisions concerning their daily care in their own homes: a review of the literature. Int $J$ Older People Nurs 2016;11:284-97.

70 Garvelink MM, Ngangue PAG, Adekpedjou R, et al. A synthesis of knowledge about caregiver decision making finds gaps in support for those who care for aging Loved ones. Health Aff 2016;35:619-26.

71 Livingston G, Sommerlad A, Orgeta V, et al. Dementia prevention, intervention, and care. Lancet 2017;390:2673-734.

72 Jacobson J, Gomersall JS, Campbell J, et al. Carers' experiences when the person for whom they have been caring enters a residential aged care facility permanently: a systematic review. JBI Database System Rev Implement Rep 2015;13:241-317. 
Correction: Systematic review of qualitative studies on participants in the decision-making process about the location of care of the elderly

Serrano-Gemes G, Rich-Ruiz M, Serrano-del-Rosal R. Systematic review of qualitative studies on participants in the decision-making process about the location of care of the elderly. BMJ Open 2020;10:e36551. doi: 10.1136/bmjopen-2019-036551.

This article was previously published with an error.

Reference 31 was incorrect. The correct reference is as follows:

Chen S, Brown JW, Mefford LC, et al. Elders' decisions to enter assisted living facilities: a grounded theory study. J Hous Elderly 2008;22:86-103.

The reference citation, therefore, in Table 1 would now be Chen et al 31 .

Open access This is an open access article distributed in accordance with the Creative Commons Attribution Non Commercial (CC BY-NC 4.0) license, which permits others to distribute, remix, adapt, build upon this work non-commercially, and license their derivative works on different terms, provided the original work is properly cited, appropriate credit is given, any changes made indicated, and the use is non-commercial. See: http://creativecommons.org/licenses/by-nc/4.0/.

(C) Author(s) (or their employer(s)) 2020. Re-use permitted under CC BY-NC. No commercial re-use. See rights and permissions. Published by BMJ.

BMJ Open 2020;10:e036551corr1. doi:10.1136/bmjopen-2019-036551corr1

A) Check for updates 